

\section{Comunicação no cinema: públicos distintos e percepção da imagem ${ }^{1}$}

\section{Communication in cinema: distincted publics and image perception}

\section{Resumo}

O texto apresenta reflexões sobre a construção do imaginário e da realidade no cinema no intuito de verificar possibilidades e contradições do cinema artístico nas contribuições de alguns teóricos, como Badiou, Godard, Huyssen e Morin. Procuramos tratar a imagem cinematográfica de Carmen Miranda na "sedução" de diversos públicos, verificamos sua persuasão, percebida ou não, sobre estes indivíduos. Consideramos as influências culturais, sociais e políticas ao analisarmos as diversas formas de interpretar e interagir com a imagem através do cinema. No meio cultural temos um predomínio de imagens visuais que fazem parte da manifestação de mudanças sociais. Muitas imagens têm interação direta com os diferentes públicos, geram diversas interpretações e seus componentes têm papel histórico registrado pelos meios de comunicação, como o cinema que tem seus distintos públicos.

\section{Palavras-chave}

Carmen Miranda; imagem; imaginário.

\section{Abstract}

The text presents reflections on the construction of imaginary and reality in film in order to verify possibilities and contradictions of art cinema in the contributions of some theorists, such as Badiou, Godard, Huyssen and Morin. We seek to treat the cinematic image of Carmen Miranda in "seduction" of various audiences, verified its persuasion, perceived or otherwise, regarding these individuals. We consider cultural influences, and social policies that made through cinema. In the middle we have a cultural predominance of visual images that are part of the manifestation of social change. Many images have direct interaction with different audiences, generate different interpretations and their components have registered historic role in the media, such as film that has its distinct audiences.

\section{Keywords}

Carmen Miranda; image; imaginary. 
Histórias marcadas pela imagem de Carmen Miranda

Temas sobre o esquema, imagem visual e representação do próprio corpo humano foram estudados por Freitas (2008), que percebeu possibilidades de processos complexos e implícitos na cognição e na exposição de interações sociais importantes. A primeira análise, sendo a imagem verificada no âmbito da visão humana, responde às interações com o meio, além da importância dos gestos e elementos que são formadores da imagem corporal. Hábitos e experiências pessoais podem variar de um indivíduo para outro. De forma geral, os efeitos visuais e os efeitos das excitações sensoriais geram consequência no corpo do indivíduo, em seguida, no comportamento deste sujeito, evoluindo para representação visual mediada que vem do próprio corpo. Inicialmente tratamos das percepções e conhecimentos que influenciam na análise de uma imagem. Em seguida, abordamos a imagem de Carmen Miranda no cinema.

Agora, se trabalharmos esses hábitos e exposições culturais marcadas por uma imagem, logo podemos buscar a figura artística de Carmen Miranda no cinema. Até mesmo retratada dentro desse quadro da imagem representada pelo corpo. Para tratarmos essa representação buscamos o longa-metragem de animação de 1944, que tem como tema o folclore e trilha sonora de Ary Barroso com o episódio Os Quindins de laiá (fig. 03-04), produzido por Walt Disney Pictures. Nesse filme também iremos tratar do imaginário produzido na população brasileira e as intenções dos estúdios da Disney.

O filme mostra a imagem de uma floresta (fig. 01), o que remete novamente ao brasileiro, é o imaginário de reconhecimento ao mostrar sua cidade ao americano. $O$ cidadão americano exibe suas ideias sobre uma cidade atrasada, mas curiosa e bela, pois tudo é novidade
- não existem mais em seu país toda esta fauna e flora. Ao longo do desenho, várias imagens nos fazem buscar conhecimentos individuais acerca da imagem de Carmen Miranda; na primeira imagem aparece a figura multiplicada em quatro do Zé Carioca vestido de baiana. Essas várias imagens do personagem com chapéu dando destaque às bananas (fig.02) como o de Carmen Miranda convidam o amigo a conhecer a cultura baia- na. Na segunda imagem surge cantando Aurora Miranda (fig.02), que é irmã da atriz.

Primeiro aparece apenas uma sombra com formato corporal de uma baiana, a população brasileira logo busca processos sociais já ocorridos no seu conhecimento e tende a imaginar Carmen Miranda. A mulher vestida de baiana (fig. 03-04) no filme é interpretada por Aurora Miranda, porém várias pessoas quando
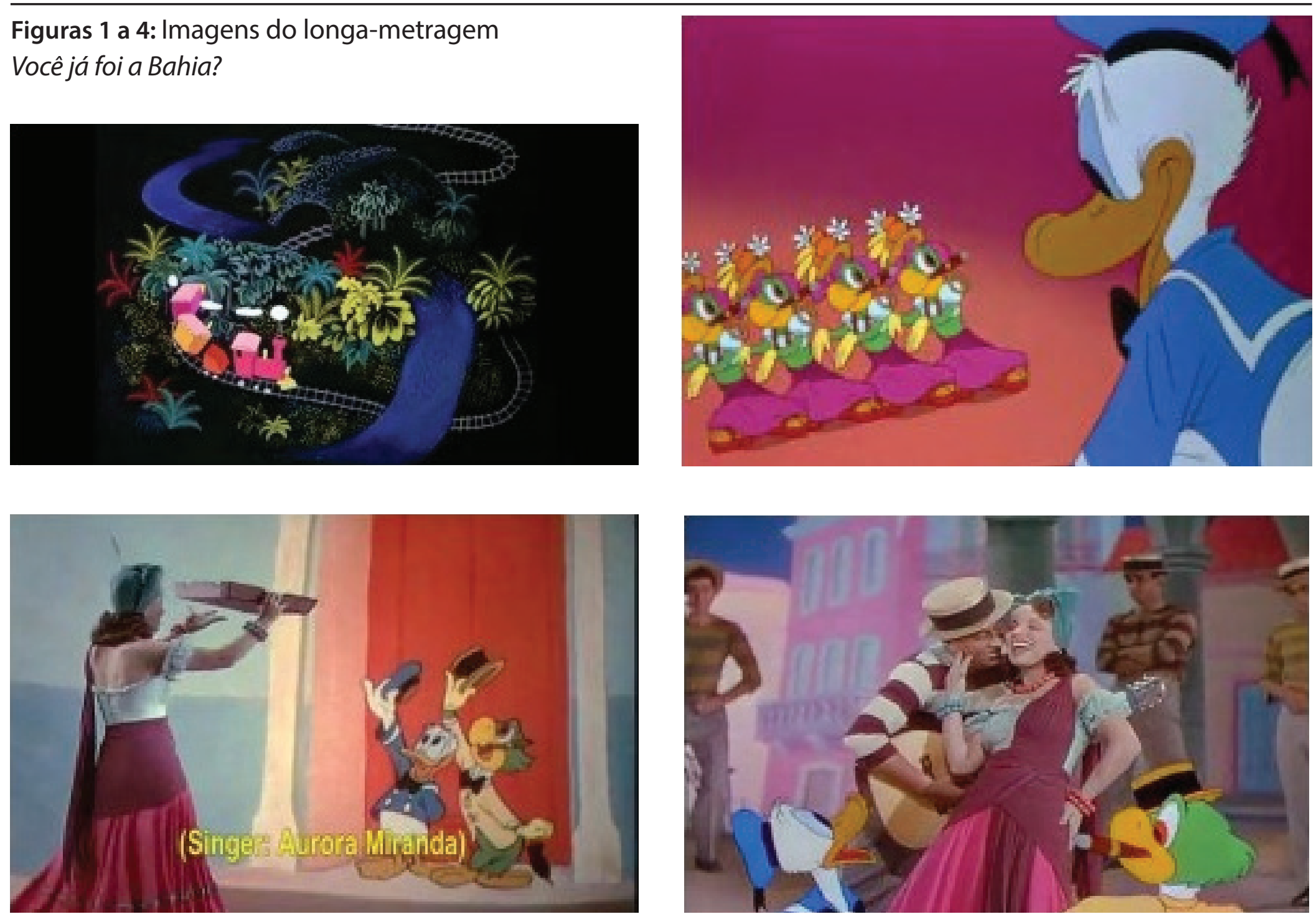

36 PORTO ALEGRE | v. 19 | n. 32 | 2014 | pp. 35-44 Sessões do Imaginário 
comentam o filme citam Carmen Miranda como a intérprete, até mesmo em estudos acadêmicos. A mulher vestida de baiana virou um símbolo brasileiro associado à pessoa de Carmen Miranda. Somente a sombra de uma mulher dançando com o personagem americano Pato Donald já nos remete em nosso imaginário a imagem corporal de Carmen Miranda com suas vestes de baiana e com seus balangandãs.

Os gestos, os movimentos e a excelente trilha sonora, nos fazem buscar nosso conhecimento verbal da história sobre o corpo atuante sambando. A seguir temos percepções e símbolos que conceituam um corpo real buscado pelas lembranças. Esses conceitos sociais, ativados por aqueles que conhecem sua imagem real, logo procuram um corpo de pele branca, mesmo que a sombra represente, no filme, a cor negra da baiana brasileira. Além de ser a mulher de um país subdesenvolvido onde dançam para alegrar. Pato Donald representa os EUA em uma visita à Bahia, marcando essa percepção da imagem americana junto ao brasileiro em uma dança típica do país.
A imagem da baiana induz a busca da memória de um registro situado em um período do tempo: a atriz Carmen Miranda vestida de baiana nos filmes norte-americanos. Zé Carioca suspira apresentando-a ao Pato Donald com a frase "como a baianinha é tão bonita" conhecida por seus "quindins de laiá", explicando ao amigo que os quindins são uma comida típica brasileira, como os biscoitos - cookies para os americanos. Donald fica "deslumbrado" suspirando com a beleza da baiana (fig.03). Na cena destacam o brasileiro e o americano juntos, "arrebatados" com a beleza da mulher brasileira.

No filme existe uma mistura de personagens, tanto de seres humanos (a mulher baiana e homens cantores) como personagens de desenho animado (Zé Carioca e Pato Donald). Mostram a disputa entre esses personagens de desenho animado pela atenção da baiana real. Em seguida, surge a banda com personagens também humanos, homens vestidos com trajes típicos das roupas usados no samba de época. Cantam o samba junto com a baiana. A seguir, Pato Donald "enciumado" per- gunta "quem é esse cara?". Zé Carioca responde: "Oh, ele é um malandro, Donald". Dessa maneira, reafirmam novamente o personagem americano como sério (Pato Donald) e o personagem brasileiro cantor e dançarino como um "espertalhão".

No desenho animado da Disney A culpa é do Samba, de 1948, em tempo de melodia, temos novamente a imagem da baiana nos induzindo à figura de Carmen Miranda (figuras 5 e 6). Essa produção é uma continuação dos filmes que colocam o personagem americano Pato Donald e outros personagens latino-americanos na intenção de conquistar parcerias e mercados latino-americanos.

O curta-metragem envolve personagens e espectadores ao samba, tropicalismo que induz às coisas boas que existem no Brasil, como o samba, por exemplo. É o mesmo objetivo do filme Você já foi à Bahia? (The Three Caballeros, Norman Ferguson, 1945): ambos buscam tratar do samba e da cultura latino-americana, além da amizade entre os países, destacada com personagens latinos e americanos.
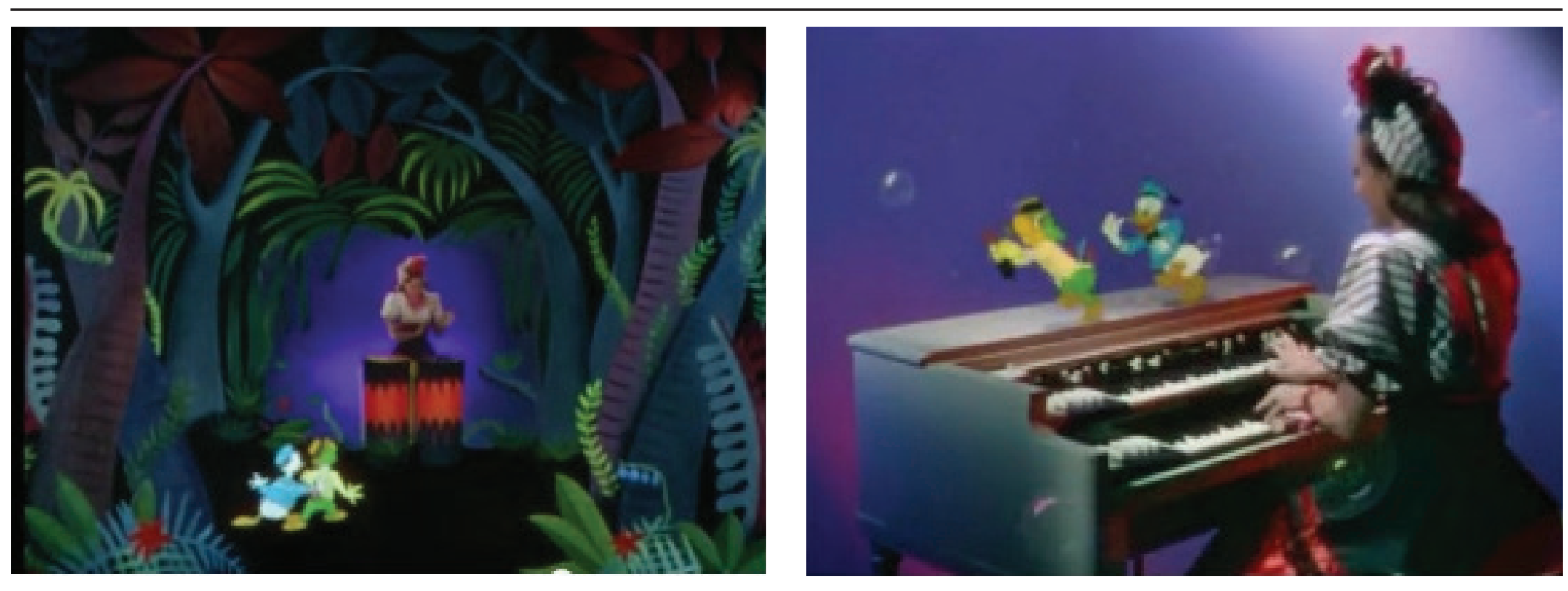

Figuras 5 e 6: Imagens do episódio curta-metragem A culpa é do samba

37 PORTO ALEGRE | v. 19 | n. 32 | 2014 | pp. 35-44 Sessões do Imaginário 


\section{Rádio Auriverde e Carmen Miranda}

Neste momento analisaremos as sensações e concepções que as imagens podem proporcionar no indivíduo (des)informado. O documentário Rádio Auriverde, do cineasta Sylvio Back, foi elucidado por Tomaim (2003), que analisou o audiovisual incomum de Carmen Miranda e do Brasil no período da Segunda Guerra Mundial. Os filmes de Back eram feitos para provocar e fazer com que o espectador pensasse, buscando no passado o brasileiro heroico e sagrado. O documentário cobria a história política e os rearranjos ideológicos da população especialmente registrados pelo discurso oficial no período da Segunda Guerra Mundial. Sylvio Back soube proporcionar desconforto nos espectadores.

$O$ intuito de analisarmos esse documentário é verificar os verdadeiros interesses dos EUA em relação à população brasileira, já que ocorreu no período da Segunda Guerra Mundial, mesma época em que a imagem de Carmen Miranda já fazia sucesso tanto no Brasil quanto nos EUA. O "mundo da guerra" invadia o imaginário de quem assistia ao filme na voz do Repórter Esso. Um exemplo desta explanação foi a frase: "E! Atenção. Atenção Rio. O Brasil acaba de declarar guerra às potências do eixo... $O$ governo Vargas determinou a convocação de reservistas para formação das forcas expedicionárias brasileiras...". Tomaim (2003) chamou de "invasão psicológica" por ser um campo desconhecido. O documentário Rádio Auriverde soube confundir a população brasileira a respeito da presença imaginária da Força Expedicionária Brasileira (FEB) invadindo a Itália em 1944, quando o conflito já estava no fim. Uma rádio clandestina que de forma desregrada transmitia musicalmente o conflito da guerra. Foi feita uma montagem no Departamento de Imprensa e Propaganda (DIP) produzindo colagem de recortes de cinejornais de matérias do Cine Jornal Brasileiro e nos
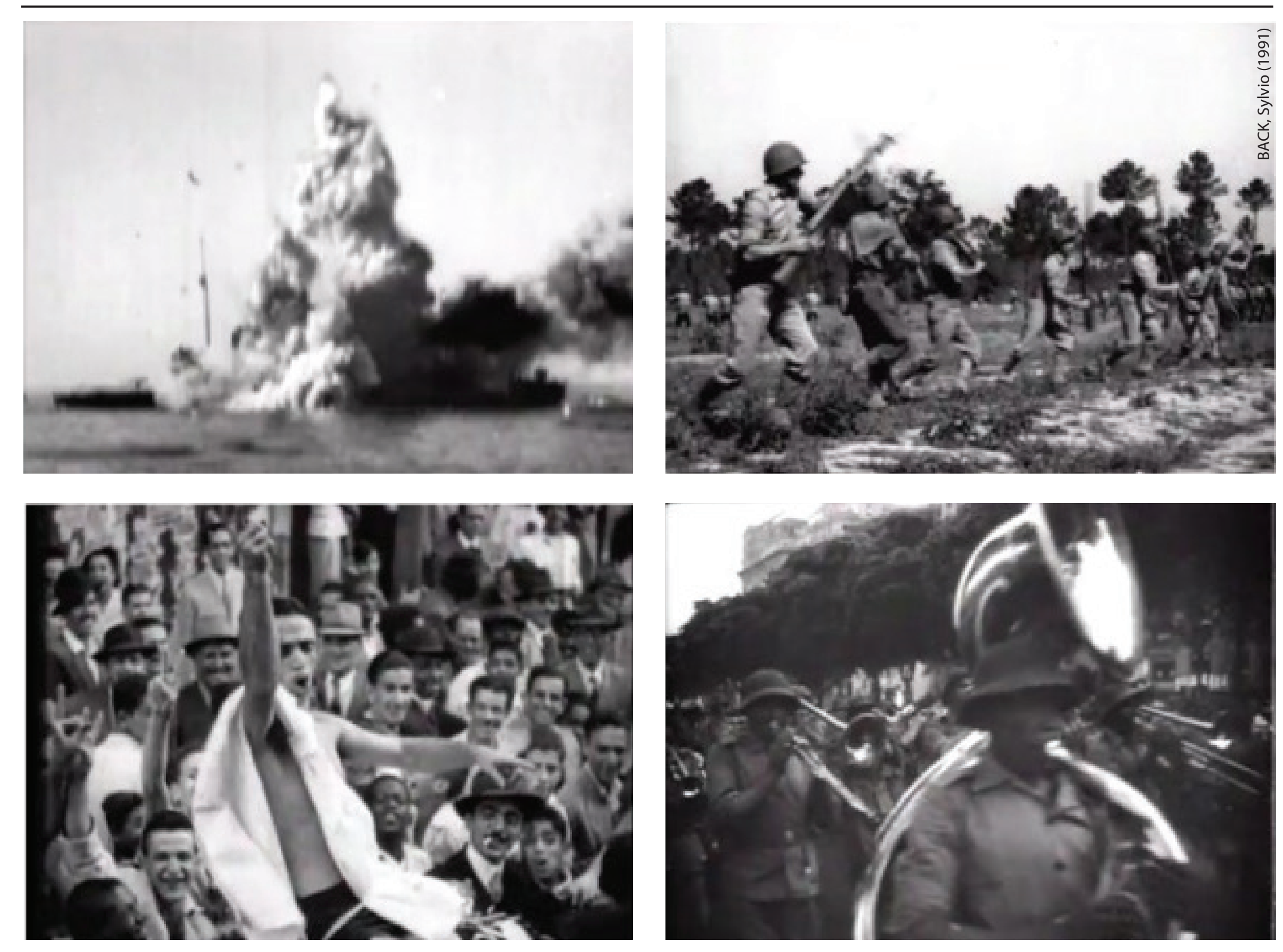

Figuras 7 a 10: Imagens do documentário Rádio Auriverde

Us Army e Us Signal Corps dos EUA. Apareciam imagens da guerra e do povo aplaudindo a decisão do governo, acompanhados da banda do exército (figuras 07-10).

O cineasta usou de sons e imagens da própria guerra em um procedimento de abdicação do discurso oficial usado com a população. Empregou o emocional atribuindo novo sentido ao filme, mostrou o outro lado que não havia sido considerado pela população. Tomaim (2003) garante que Sylvio Back exibiu no documentário uma realidade através do imaginário

38 PORTO ALEGRE | v. 19 | n. 32 | 2014 | pp. 35-44 Sessões do Imaginário 

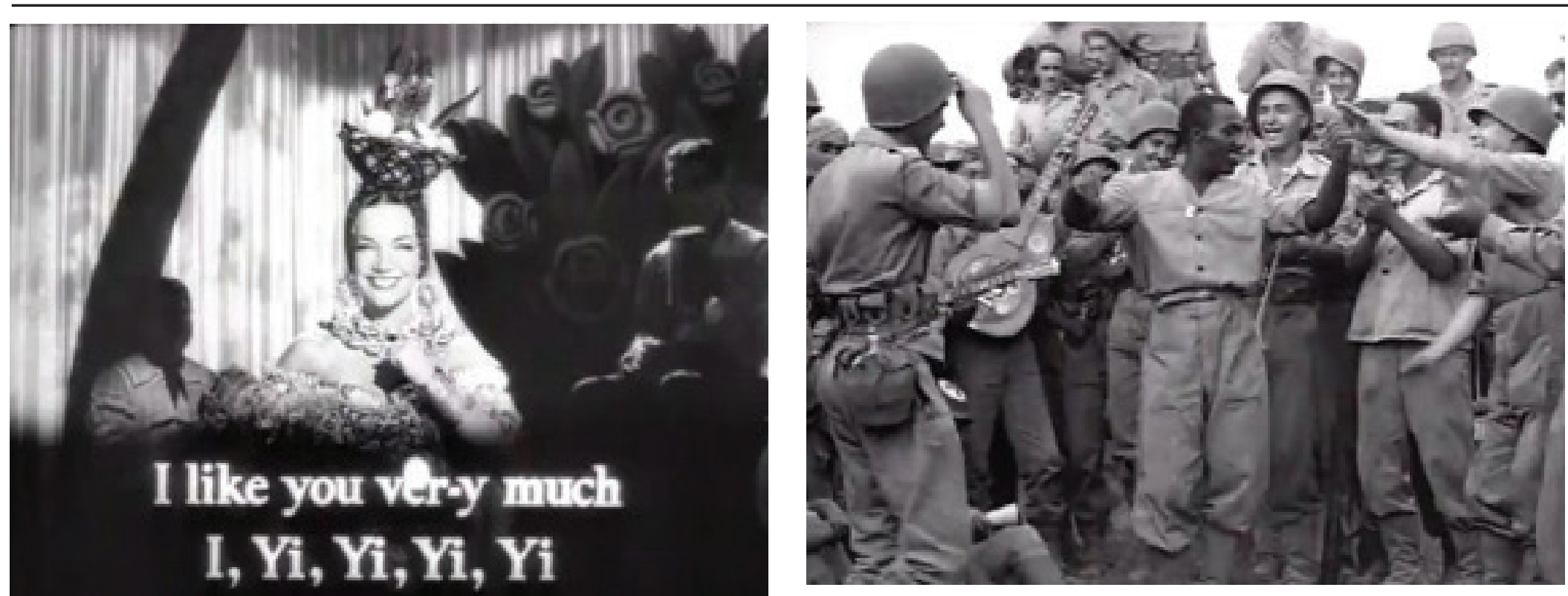

construído no filme. O desígnio foi mostrar o brasileiro enviado à guerra como moeda de barganha entre as transações brasileiras e americanas para construção da Companhia Siderúrgica Nacional (CSN) em Volta Redonda. Mas o exército do Brasil tinha toda uma reserva simbólica da sua companhia de fuzileiros da FEB e sentiu-se ridicularizado no filme Rádio Auriverde. Foram várias as manifestações de ex-combatentes no Cine Ritz, em Curitiba, ao cineasta Back.

Nesse segundo momento tratamos da imagem de Carmen Miranda. Sua figura foi usada pelos filmes norte-americanos, também nesse período, para representar a imagem brasileira, além de ter sido empregada pelo cineasta no documentário Rádio Auriverde com intuito de provar a brasilidade corrompida pelo imperialismo americano. Carmen Miranda nasceu em Portugal e tinha culturalmente identidade brasileira. Mudou-se para o Brasil ainda criança e em Rádio Auriverde sua imagem compunha um elemento artístico no início e no fim do filme. Cantou Tico-tico no fubá em português na sequência inicial do filme e, na última, em inglês.

Para Tomaim (2003), a mudança de idioma foi a representação do fechamento do ciclo da vitória americana. Carmen Miranda era a imagem brasileira estereotipada pelos americanos. O documentário Rádio Auriverde nos mostra a própria desmistificação dessa imagem. Back desconstruiu um imaginário tramado por uma ditadura que não nos proporciona o retrato real dos fatos. O documentário também foi alterado pelo cineasta direcionando para o Estado Novo; surgem novos sentidos e reproduções no cinema de propaganda.

Rádio Auriverde expõe o outro lado da guerra, mas a população brasileira, de uma forma geral, sente-se insultada. Para Tomaim (2003), os EUA enxergaram nesse período, anos 40, a importância de criar uma estratégia com o Brasil. Conseguiram negociar bases aéreas e navais e ainda comprar borracha brasileira para reforço de guerra. $O$ uso do cinema para interesses políticos e

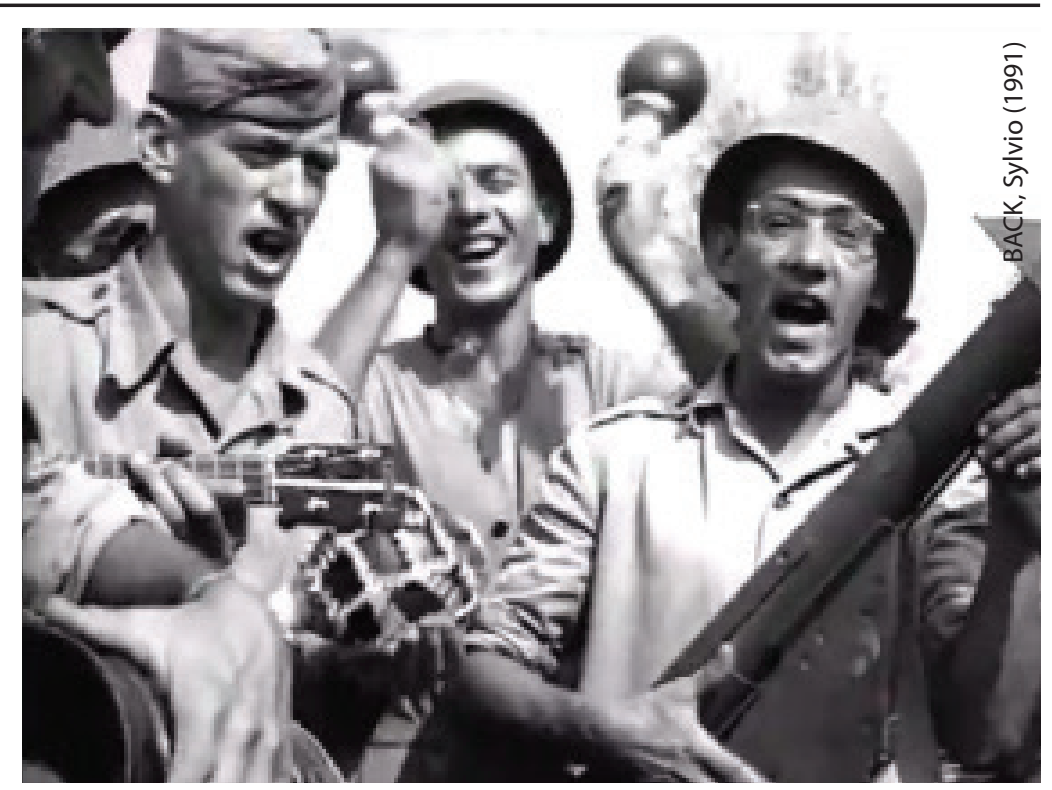

Figuras 11-13: Imagens do documentário Rádio Auriverde

comercias vem desde sua criação - o dominante manipula a maioria, seja na produção ou na distribuição. Muitos cineastas, diretores e produtores não veem outra saída a não ser a submissão ao controle da produção de filmes hollywoodianos. Esses filmes criam imaginários e modificam as atitudes da sociedade; temos como exemplo a "brasileira" Carmen Miranda que contribuiu simbolicamente na visão positiva dos brasileiros perante a sociedade norte-americana.

Realmente a imagem de Carmen Miranda tinha essa relação que combinava crenças, sentimentos positivos e atitudes sociais da cultura brasileira com os EUA, seja ela imaginária ou não. Analisamos que mesmo antes de fazer cinema a artista já tinha seu nome conhecido pela população na chamada "era de ouro" das rádios brasileiras. O cineasta buscou retratar a manipulação do EUA sobre o Brasil usando da imagem de Carmen Miranda, que era conhecida e que representava o brasileiro. Quando a atriz cantou em inglês (fig. 11), na

39 PORTO ALEGRE | v. $19 \mid$ n. 32 | 2014 | pp. 35-44 Sessões do Imaginário 
cena final do documentário, o cineasta ora mostrava as imagens de militares brasileiros (fig.12) em campo de guerra cantando e dançando o samba, ora voltava para a imagem de Carmen Miranda cantando, e sempre ao som da música Tico tico no fubá, para mostrar a intenção de aproximação dos países.

Em determinado momento é trocada a letra da música de Carmen Miranda pela do Hino Nacional Brasileiro. Inseriu-se o instrumental no ritmo de melancolia e tristeza contradizendo as imagens dos soldados inocentes que dançam felizes na guerra. Nesse sentido, entendemos que os militares exibem suas armas (fig. 13) como elemento de poder. Na mesma cena volta a imagem de Carmen Miranda (fig.11). Associam ambas as imagens, Carmen Miranda e os militares brasileiros, unidos no contentamento de lutar por um país que não é o deles, uma luta que era dos americanos.

O cineasta Back quis mostrar a imagem de Carmen usada a favor dos EUA. Independente de sua identidade brasileira, ela era o melhor exemplo para mostrar o quanto o Brasil estava buscando o direito de inserir o modo de ser americano nas raízes brasileiras. $\mathrm{O}$ imaginário do cidadão brasileiro é motivado a desejar um dia ser um país desenvolvido.

O cinema pode distorcer a cultura de outros países. Tomaim (2003) garante que nos longas-metragens de Hollywood a atriz tinha forte representatividade no desconhecido universo da "guerra psicológica" entre os Estados Unidos e Brasil. Os filmes não impunham as verdades absolutas, o espectador não era convidado a pensar, as mistificações não eram para todos os países. Retratavam os interesses e despertavam o "imaginário" do consumidor como forma de sedução. Tomaim (2003) garante que não se sabe mais o que é impressão do real e o que é imaginado no cinema. $O$ indivíduo assiste e acredita que seja verdade.
O sucesso que Carmen Miranda fez internacionalmente com o cinema de Hollywood facilitou a associação que Sylvio Back quis fazer da imagem brasileira corrompida pelo desejo de estar com os americanos. Ao mesmo tempo, mostram a imagem dos soldados inconscientes naquela manipulação americana. A questão está na sua imagem usada a favor da influência americana sobre a população brasileira em benefício dos EUA, imagem esta que mostra o lado invertido no desígnio dos EUA com o Brasil. Tanto que o documentário, de forma geral, não foi bem visto pela população brasileira. Notamos nessa produção que a mídia tentou indicar aos brasileiros as "verdadeiras intenções" dessa imagem mostrada pelos americanos de forma positiva para com os brasileiros.

No entanto, o documentário não poderia ter aceitação imediata dentro de uma cultura onde sua população pensava diferente da realidade que o cineasta tentou expor. Soldados brasileiros e a atriz Carmen Miranda são imagens da igualdade americana com a brasileira, em prol de uma mesma luta de ideais, que para os brasileiros não importava se eram ideais americanos, apenas que eles estavam juntos lutando por uma mesma causa. $O$ interesse dos brasileiros naquele momento era ser igual independente se era ilusório ou não.

\section{Análise da arte e do imaginário} cinematográfico com Carmen Miranda

Os teóricos que serão mencionados não trataram da atriz Carmen Miranda, no entanto, seus estudos servem para refletirmos sobre a leitura da figura imaginária da atriz. Buscamos alguns autores que tratam a imagem e prendemos suas teorias ao cinema. Como estamos abordando a imagem de Carmen Miranda, buscamos o longa-metragem de animação Você já foi à Bahia? da Disney, antecedido por Saludos Amigos, que teve o in- tuito de conquistar a população da América Latina, além de verificarmos a utilidade da imagem na sedução e no imaginário cinematográfico. A junção da arte e da técnica é necessária, elas não podem estar separadas, de acordo com Godard (1989). Não há como definir o quanto de cada um, pois o cinema é um experimento, algo que sempre poderá ser feito de outra forma.

Perdura no tempo a opinião de que o filme sempre continuará criativo independente de quando foi feito; faz toda a diferença a produção do filme na hora de criar. Continuará existindo o autor do filme em seu contexto artístico, como também, influenciará o ambiente onde foi realizada a filmagem para dizer que o cinema teve arte, autonomia e infraestrutura. Godard (1989) considera que o cinema nem é arte nem é técnica, mas sim um "mistério". O enquadramento usado em uma filmagem agrega poder na sua proposta, fazendo com que o outro participe da construção do filme.

Não há como pensar em cinema sem falarmos da memória que possibilita construir o imaginário. Godard (1989) afirma que o cinema é essencialmente realista. Um imaginário que produz esquecimento e memória. Com o recuo no tempo cada um irá construir sua memória. Para Huyssen (2000) não temos mais essa ideia de progresso, pois nós vivemos o progresso. Voltamos para o passado e construímos a memória. O tempo já nasceu desconstruindo o espaço, enquanto o cinema já nasceu desconstruído, brinca com essa noção de tempo e espaço. $O$ cinema precisa desse recuo ao passado, uma busca da memória para compreender o atual e em seguida construí-lo. Ao pensarmos em uma imagem de algum ator no cinema em décadas passadas, por exemplo, estamos edificando nossa memória.

O conceito da memória seria algo construído pelo passado, lembrando esta "musealização" como algo já 
decorrido, que gerou um "estouro" no número de biografias. O passado está no presente, porém serve mais para "banalização" do que para própria lembrança da memória. Ocorre reinvenção da arte. Para Huyssen (2000), a memória tornou-se uma construção de mitos, considerando uma reação a globalização. A mídia é que pode produzir essa amnésia. Huyssen (2000) compara com a lembrança do holocausto que nos permitimos esquecer. $O$ esquecimento vem de algo didático, sendo mais explicativo ou mesmo uma representação. Ao contrário da redenção ao real que vem da abstração e da subjetividade.

Temos a necessidade do passado porque o presente é muito curto e tem relação com o espetacular. Existe uma amarração dessa ligação do passado com o presente. Huyssen (2000) exemplifica com a mídia, compara com a "aura" que é transcendente e gerada na atualidade, relacionando a computação como algo que facilita o copiar. Seria fazer de forma diferente do que já é feito na digitalização atual. Para o autor, conseguimos de alguma maneira criar alguma coisa que considera ser um processo manipulativo.

O ser humano tem uma incapacidade de lembrança, diferenciando-se de um indivíduo para o outro. Conseguimos nos colocar no lugar do outro, nossas análises tendem a variar com nossas diferenças. $O$ irrepresentável é o que conseguimos ver no outro, buscando fazer a diferença, algo que não seja aquilo que já vimos tantas vezes. Se o "eu" trabalha a abstração e a subjetividade, o "eu" consigue aproximar-se dessa diferença do outro. $O$ representar é colocar-se no ambiente do outro. A sociedade é a fonte desse real onde o cineasta trabalha esta realidade e produz algo atual, dando retorno ao espectador. Quem assiste irá ter uma reação, provocando um ciclo vicioso. A partir dessa noção o espectador constrói o imaginário buscando arquivos de memórias.
O filme, para Morin (1970), é algo que vem da nossa realidade, o cinema é uma construção desta realidade que permite ao espectador fazer relações da história contada no filme. O cinema trata a identificação e projeção da realidade. Podemos buscar novamente o cinema com Carmen Miranda relacionando sua imagem visual de baiana que tem origem no Estado da Bahia, no Brasil. Usou dos trajes e da dança buscados no modo extrovertido de ser da população brasileira, aquilo que faz parte dos costumes deste povo. Analisando a teoria de Morin (1970) e a relacionando a Carmen Miranda, logo pensamos a figura da atriz de forma imaginada por muitas populações de culturas diferentes que buscaram aproximar sua imagem as suas realidades, costumes e etnias.

Imagem esta que era totalmente nova para alguns, como os americanos e europeus, mas que permitia a esses povos buscarem imaginar como era a vida dessa sociedade brasileira, pensar as origens e raízes desta figura. Alguns tinham mais dificuldade de compreender o que a imagem de Carmen Miranda significava, por representar muito mais uma figura de determinada região (Estado da Bahia) e algumas relações ao próprio Brasil (frutas e música) do que realmente uma figura típica brasileira. O que gerava certa dificuldade para alguns indivíduos em relacionar a realidade brasileira aos filmes. Para construir uma imagem brasileira seria preciso inserir muita informação nessa figura, já que o Brasil é uma mistura de raças e culturas.

Carmen Miranda participou de muitos filmes que eram vistos por vários países e compreendidos da maneira que cada espectador desejava. O indivíduo busca seus arquivos passados - como analisamos nas teorias de Edgar Morin - que irão variar de acordo com o seu conhecimento. Nas ideias de Jean-Luc Godard podemos perceber que o ambiente interferia diretamente no contexto produzido pelos cineastas nos filmes com Carmen Miranda. A construção dos filmes era realista, a população construía o imaginário de estar junto com os EUA ao buscar sua memória. Carmen Miranda era um produto brasileiro contado pelos norte-americanos nos filmes de Hollywood, assistiam a uma mistura de Brasil e EUA nas paisagens exibidas.

Buscando Huyssen (2000), entendemos que ao pensarmos em Carmen Miranda, logo pensamos o cinema como algo trabalhado pela mídia hollywoodiana. Esquecemos o que não queremos ver e lembramos apenas do que interessa. Carmen Miranda era real e nos permitia render ao abstrato e subjetivo. Hollywood produziu uma armação dessa figura baiana em diversos países, buscou as diferenças do outro e tornou Carmen Miranda um mito global. Agradando ou não a todos, foi aprovada pela massa popular internacionalmente. Carmen Miranda despertou o imaginário de diferentes públicos com a mesma imagem e gerou diferentes imaginários, seja por interesses ou por informações já existentes nos arquivos de algumas populações, ou mesmo, por ambos os motivos. Cada vez mais o cinema precisa proporcionar ao espectador um momento de conforto.

Tratando as ideias de Alain Badiou, buscamos novamente a imagem de Carmen Miranda. Badiou (2002) afirma que seria preciso o entrelaçamento das imagens para construir o pensamento. $O$ autor resume o cinema como uma visita ao filme e que a arte não é uma parte sensível, afirma sugerir a ideia de algo que venha da estética. $O$ cinema será entendido no momento dessa passagem do indivíduo ao visitar o filme. $\mathrm{O} \mathrm{im-}$ portante são os movimentos do filme. Badiou (2002) é um dos poucos autores contemporâneos ligados principalmente à arte, define o cinema como global, apenas uma passagem. Diferente de um cinema em movimen- 
to local onde a ideia é outra coisa do que ela realmente é. Além de considerá-lo também como cinema impuro, uma mistura de outras frentes artísticas que hoje é comum serem chamadas de movimento pós-moderno.

$O$ autor refere-se ao filme como uma ideia do espanto, o quanto é difícil existir e ao mesmo tempo não assustar com o maléfico. Badiou (2002) ainda associa a arte com a educação no sentido de cultivar. Considera que precisamos da filosofia para pensar a arte, visualizando-a como uma invenção. O autor busca três esquemas. A didática busca aproximação do efeito no outro para nos aproximar mais da realidade daquele efeito real que pode nos proporcionar. Exemplifica com a educação e a filosofia. O segundo seria o romântico, que tem a preocupação do prazer - mas sabemos que este prazer não é perfeito. A arte faz o que a filosofia não poderia encontrar de certa forma, a arte encarna o sujeito nesse esquema romântico que podemos considerar que seria a valorização do que é ou não arte dos autores.

O último esquema é o clássico, que se subdivide em duas teses, sendo a arte que tem ligação com o didático incapaz da verdade que se encontra na ordem da aparência. Para Badiou (2002), a segunda tese seria a preocupação da arte e não da verdade; a arte seria uma ideia de imaginação do outro. No didático a arte tem direito a tudo e no romântico a arte tem efeito em tudo. No clássico, o importante é o que pode ou não, seria a arte a partir da ética. Considera o marxismo como didático. A psicanálise é a arte, pois tem essa ideia de desejo. A hermenêutica busca a ideia mais do romântico, exemplifica com a arte que tem o artista no seu momento de romântico pensador.

Por último, o romântico busca a verdade daquilo que não era falado, mas que não deixa de existir uma saturação, faz com que os esquemas ainda continuem presentes. Se pensarmos em vanguardas, logo pode- mos concluir que elas acabam, pois são da ordem da representação e não da relação. Badiou (2002) ainda entende a arte como um pensamento onde as obras são reais. Não existe preocupação com que o efeito da arte irá proporcionar. As verdades são artísticas e políticas, mas nunca são filosóficas e nem serão o lugar da verdade. $\mathrm{O}$ cinema tenta buscar as verdades mais do que o próprio sentido, resgatando a verdade e não ao contrário, que para o teórico seria criar verdades reais.

Partindo de Alain Badiou para tratarmos novamente a imagem de Carmen Miranda, logo podemos pensar que Hollywood não leu as teorias do autor, já que os filmes de Carmen Miranda foram criados pelo cinema como verdades reais, estabeleceram tais verdades e não de acordo com o que o autor sugere que seria buscar as verdades para construir o filme. Mas, por outro lado, Hollywood conseguiu ligar a construção do pensamento do espectador ao cinema que relaciona Carmen Miranda, interpretando e cantando as suas origens e costumes tropicais. Fez o público participar dessa transição de movimento buscando sua imagem de brasileira no cinema hollywoodiano.

Agora, buscando tratar da imagem de Carmen Miranda com todas essas teorias do imaginário, analisamos o longa-metragem de desenho animado Você já foi à Bahia?

Verificando as teorias de Andreas Huyssen, logo percebemos que dificilmente conseguimos nos colocar no lugar do outro. No caso do desenho animado Você já foi a Bahia? podemos buscar suas ideias e interpretar o brasileiro e o mexicano que mesmo ao lado do importante americano Pato Donald induzem o espectador a continuar a buscar seus arquivos na memória, mesmo sabendo que os países latinos são diferentes dos norte-americanos. Mesmo que o filme tente mostrar o contrário.

Mas na abstração do "eu" conseguem se sentir amigos do americano naquele momento que cantam e dan- çam juntos em um passeio para comemorar o aniversário do Pato Donald. O personagem mexicano (Panchito, o galo) recepciona os amigos apresentando seu país. As cenas dão ênfase à cultura mexicana e ao gosto dos amigos - o brasileiro (José Carioca, o papagaio) e o americano (Donald, o pato) - por estarem naquele passeio juntos. No entanto, não deixam de aumentar o valor (fig. 14) ou mesmo o prestígio de ser cidadão americano. Nesse momento, param de destacar o Panchito e destacam Donald. Entretanto, como a intenção de Hollywood é conquistar os latino-americanos a Disney escolheu o personagem certo, Pato Donald, mesmo sendo uma "estrela" de Hollywood não deixa de ser atrapalhado e a música de Dorival Caymmi é cantada por Zé Carioca.

A garota brasileira (fig. 15) encontrada pelo trio de amigos em passagem pela Bahia remete-nos novamente a imagem de Carmen Miranda. Além de sugerir a beleza da mulher brasileira reconhecida por diversos países, nesse período a atriz era muito conhecida. São os arquivos dos espectadores acionados no momento em que assistem a imagens do filme, algo que não precisa ser dito, e sim relacionado a uma verdade vivenciada por este espectador. Diferentemente do personagem Donald, Mickey Mouse (fig. 16) foi outro personagem da Disney - esperto e inteligente - que aparece em Você já foi à Bahia?. Ele é apenas um apresentador dos três cavaleiros sem ter muita ênfase em seu papel, diferente do seu personagem nos outros desenhos marcado por ser inteligente/educado.

Brasileiro e mexicano apresentam-se com fortes apertos de mãos, orgulhosos por conhecerem Mikey Mouse. Pato Donald não demonstra estar impressionado com sua presença, já que também é uma estrela de Hollywood. Logo, Mickey Mouse apenas é o apresentador de TV, o destaque continua sendo para os três amigos que dançam no palco. Em seguida, Pato Donald 

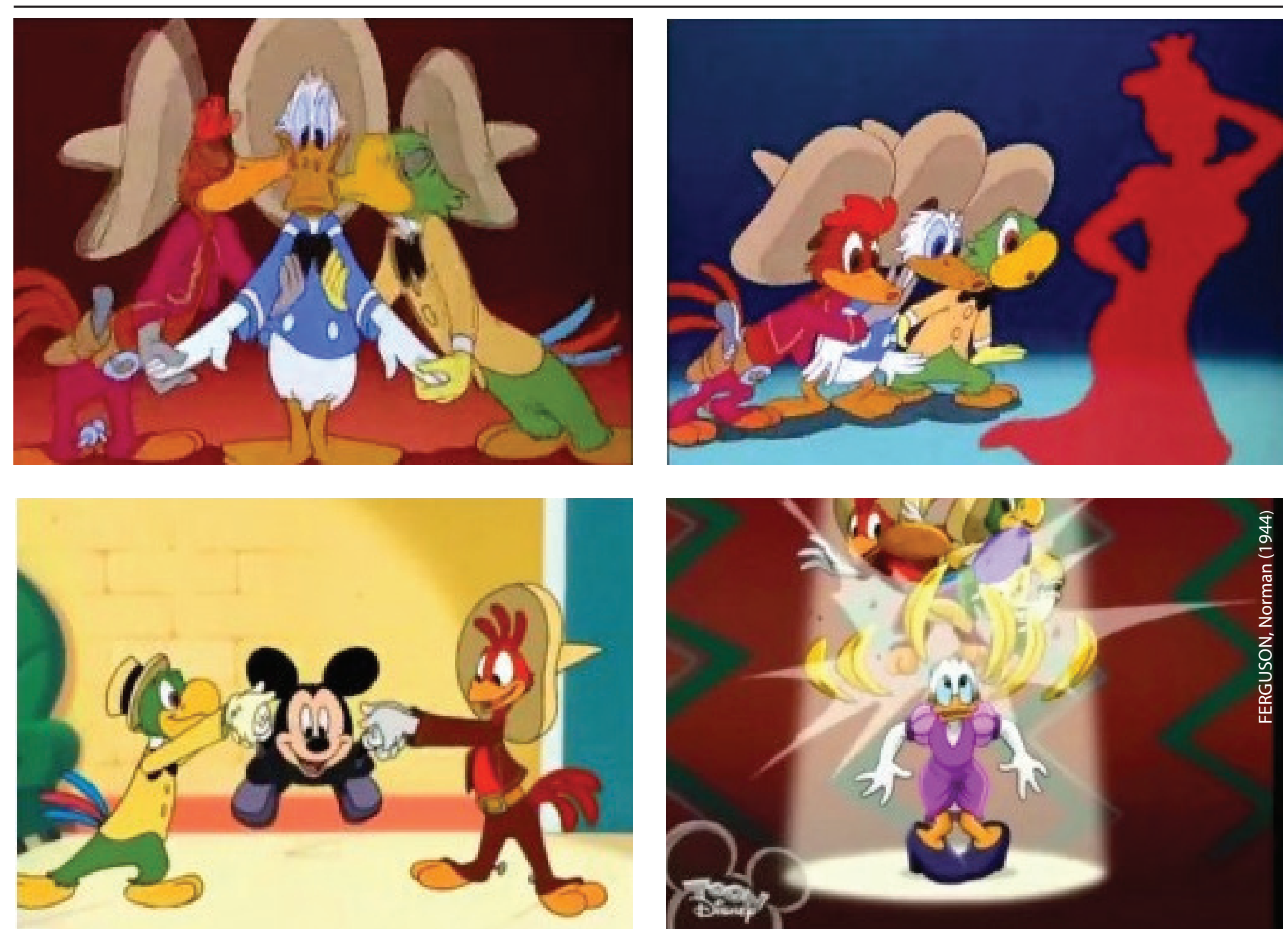

Figuras 14 a 17: Imagens do longa-metragem Você já foi à Bahia?

sai vestido de baiana (fig.17) de baixo dos chapéus mexicanos, remete- nos novamente a imagem de Carmen Miranda. Mostram Pato Donald sentido-se ridicularizado, logo, saem os dois amigos do seu chapéu de baiana, que estão afinizados com as vestes típicas e os apetrechos tropicais. $O$ chapéu tem uma mistura de produtos que lembram o México e o Brasil sendo usados, ou mesmo aceitos pelo personagem americano.

Você já foi à Bahia? admite brasileiros e mexicanos como personagens espertos e cheios de malícia, também tem o lado do companheirismo ao mostrar a beleza dos produtos típicos de seus países ao amigo americano que sempre se mostra interessado e curioso. Existe destaque para o nome Brasil e México nos livros e o longa dá a entender que está contando uma história destes países latinos ao personagem dos EUA. Além disso, sempre são colocadas cenas de baianas que nos fazem pensar em Carmen Miranda - sua imagem é sugerida em vários momentos. No todo, ocorreu o mesmo processo no curta-metragem Aquarela do Brasil e em outros episódios como Os quindins de laiá.

\section{Considerações finais}

Percebemos no texto que a imagem tem um olhar particular de cada indivíduo ao buscar o seu mundo. $\mathrm{O}$ público para agregar representatividade na imagem a constrói com base em seus conhecimentos e costumes. Podemos comparar que a memória, de uma forma geral, é elaborada pelos europeus através da construção buscando valores simbólicos. Já para os americanos e brasileiros acontece por meio de técnica. Essa busca de informação dos brasileiros por meio técnico teve forte influência dos EUA no seu processo de industrialização. Há uma existência histórica e psíquica que o cinema antes de ser arte, é histórico, o filme já é um fato concretizado, social, político e/ou econômico. Como aceitamos, ou mesmo fomos convencidos em inserir a cultura americana em nossa cultura, tendemos a ter esse lado consumidor e valorativo da técnica.

O brasileiro sabe que Carmen Miranda foi produto divulgado e valorizado pelo meio cinematográfico hollywoodiano. Notamos nas teorias de Edgar Morin que o indivíduo, ao associar sua realidade ao filme, nos passa toda essa relação da realidade vivida por ele, o espectador. Então, mesmo que o brasileiro não gostasse daquela imagem, de um modo ou de outro, acabaria aceitando, desde que os EUA soubessem passá-la de forma reco-

43 PORTO ALEGRE | v. $19 \mid$ n. 32 | 2014 | pp. 35-44 Sessões do Imaginário 
nhecível e que despertasse algo no imaginário latino. Metz (1980) contribuiu principalmente ao afirmar que o espectador sabe se está sonhando, ele assiste ao filme e sabe se é real ou não, ele se deixa iludir. Dessa maneira, o registro da imagem de Carmen foi reconhecido e aceito pelo brasileiro, não foi enganado, apenas preferiu aceitar a situação que achava confortável ou favorável.

Sabemos que o filme trabalha de alguma forma o que vivemos, como relatamos nas ideias de Edgar Morin. Como a rejeição inicial da forma como era colocada pelos norteamericanos a imagem de Carmen Miranda, no cinema de Hollywood, naquela época, era da elite brasileira, uma parcela muito pequena da sociedade, ou seja, classe culturalmente favorecida de conhecimento. A realidade mostrada aos brasileiros nos filmes de Hollywood tinha diferentes interpretações individuais em uma mesma população. $O$ público interagia de forma diferente com a imagem de Carmen Miranda através do cinema.

Lembrando que as imagens precisam ter entrelaçamento, para Alain Badiou, como foi visto no texto. Precisa existir uma sequência de movimentos para construir o pensamento na busca do outro, para aproximarmos da realidade. Nesse momento retorna a imagem de Carmen Miranda que representou para o brasileiro sua passagem para um país poderoso e sedutor, junto à cultura americana e o modo de vida que foram cedidos para os brasileiros. Enquanto para os americanos a alegre e engraçada figura divertia um país diante da guerra e com problemas políticos. Realidades diferentes diante de uma mesma imagem que o cinema de Hollywood usou para seduzi-los.

Percebemos, através de todo o contexto, que o texto de um filme é muito mais construído do que quando tentamos descrever o pensamento de um sonho, vimos isso nas ideias de Christian Metz (1980). O cinema precisa edificar seu discurso o mais próximo do realismo, precisa inspirar-se em uma verdade. A imagem de Carmen Miranda foi realizada em cima de uma identidade visual única, a baiana em um imaginário populacional brasileiro sendo reconhecida como atriz e cantora brasileira em Hollywood.

Os americanos adoravam aquela figura engraçada, mas pouco importava de onde ela tinha vindo e qual a sua identidade. Carmen Miranda foi uma imagem diversificada e original que conseguiu criar um mito através do cinema de Hollywood. Seus costumes, valores e tradições foram estereotipados pelo cinema americano em um visual que agradou principalmente às populações norte-americanas. Em seguida foi aceita pelos próprios brasileiros e logo ficou conhecida internacionalmente. Criou uma imagem que representou a americanização principalmente do Brasil e garantiu apoio político e econômico aos americanos do início ao fim.

\section{Referências}

BADIOU, Alain. Pequeno manual de inestética. São Paulo: Estação Liberdade, 2002.

FREITAS, Neli Klix. Esquema corporal, imagem visual e representação do próprio corpo: questões teórico-conceituais. Revista Ciências \& Cognição, v. 13, n. 3, p. 318-324, 2008.

GODARD, Jean-Luc. Introdução a uma verdadeira história do cinema. São Paulo: Martins Fontes, 1989.

HUYSSEN, Andreas. Seduzidos pela memória. Rio de Janeiro: Aeroplano, 2000.

METZ, Christian. Linguagem e cinema. São Paulo: Perspectiva, 1980.
MORIN, Edgar. O cinema ou o homem imaginário: ensaio de antropologia. Lisboa: Moraes Editores, 1970.

TOMAIM, Cássio dos Santos. Rádio Auriverde, a história (RE) afirmada: uma leitura do filme documentário como (RE) constituição do real. Revista Nucleus, v. 1, n. 1, 2003.

\section{Referências audiovisuais}

KINNEY, Jack. A Culpa é do Samba. In: Tempo de Melodia. [Filme-vídeo]. Produção Walt Disney, direção Jack Kinney; Clyde Geronimi; Hamilton Luske; Wilfred Jackson. EUA, 1948. Animação. 75 min. color. son.

BACK, Sylvio. Rádio Auriverde. [Filme-vídeo]. Direção de Sylvio Back. Brasil, 1991. 70 min. pb. son.

FERGUSON, Norman. Você já foi à Bahia? [Filme-vídeo]. Produção Walt Disney, direção Norman Ferguson. EUA, 1944.72 min. color. son.

Os Quindins de laiá. In: Você já foi à Bahia? [Filme-vídeo]. Produção Walt Disney, direção Norman Ferguson. EUA, 1944. 72 min. color. son.

Notas

1 Apoio de bolsa de estudo PROSUP/CAPES.

2 Doutora em Comunicação Social pela Pontifícia Universidade Católica do Rio Grande do Sul (PUCRS). Professor da Escola de Design da Universidade do Estado de Minas Gerais (ED/UEMG - Av. Antônio Carlos, 7545, CEP 31270-010, São Luiz, Belo Horizonte/MG, Brasil).E-mail: elianest2002@yahoo.com.br. 